\title{
QUALIDADE DE VIDA NO TRABALHO
}

O tema "qualidade de vida no trabalho" enquanto linha de pesquisa da Administração é recente, apesar das demandas de bem-estar serem antiqüíssimas. Atualmente, as maiores contribuições teóricas estão nas interfaces de saúde e segurança ocupacional, gestão da qualidade e produtividade, visão biopsicossocial da pessoa no trabalho coletivo e sustentabilidade socioeconômica. Optando por destacar aspectos da promoção da qualidade de vida, a professora Ana C ristina Limongi-França, da FEA-USP, coordenadora do N úcleo de Estudos e Pesquisas em Gestão de Qualidade de Vida no Trabalho (NEP-GQVT), recomenda os seguintes livros:
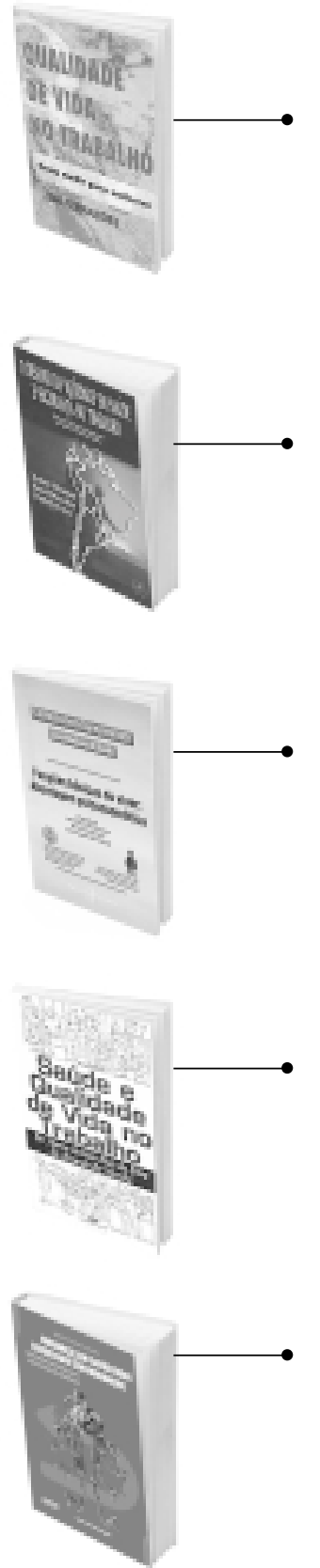

QUALIDADE DE VIDA NO TRABALHO: como medir para melhorar. Eda Conte Fernandes. São Paulo: Casa da Qualidade, 1996. $118 \mathrm{p}$.

Conceituar e criar uma metodologia empresarial capaz de revelar as complexas práticas de qualidade e produtividade no âmbito da qualidade de vida é a proposta pioneira desta obra. A autora destaca a relação entre a busca de rentabilidade nas empresas e a força de trabalho, sendo que esta última, cada vez mais conscientizada e instruída, não aceita com facilidade trabalhar em condições pouco adequadas. 0 livro também aborda a descrição de auditoria operacional, sua aplicação e resultados encontrados como fatores determinantes de qualidade de vida no trabalho.

O DESAFIO DA EQÜIDADE EM SAÚDE E SEGURANÇA DO TRABALHO: temas de saúde ocupacional nos países da América Latina. Zuher Handar, René Mendes e Ruddy Facci. São Paulo: BID - Editora VK - ICOH2003, 2004. 288 p. A obra trata do debate científico sobre a saúde e segurança ocupacional, sendo organizada pelos mais ilustres representantes desse tema na América Latina. A eqüidade em saúde e segurança no trabalho é discutida nas diferenças entre a morbidade e a mortalidade, no desenvolvimento de um modelo de saúde do trabalhador da América Latina, na eqüidade como justiça natural e igualdade como direito natural, e nos sistemas de seguridade. 0 livro finaliza com estudos de profundidade psicossocial e visão sociopolítica.

FUNÇÕES BÁSICAS DO VIVER: abordagem psicossomática. José Carlos Riechelmann, Maria Rosa Spinelli e Carlos Lagana de Andrade (Orgs.). São Paulo: Frôntis Editorial - ABMP/ APM, 1998. 196 p.

Esta coletânea proporciona bases para os seguintes aspectos: a compreensão conceitual da psicossomática como um sal to de qualidade em saúde; a visão contemporânea dos aspectos filosóficos e neuropsicológicos das relações entre o cérebro e a mente; o estilo de vida e o estresse; e as polêmicas em psicossomática, como os efeitos clínicos da fé, além de questões de gênero. A obra possui enfoque multidisciplinar de pesquisadores e profissionais da Associação Brasileira de Medicina Psicossomática.

SAÚDE E QUALIDADE DE VIDA NO TRABALHO. Marco Aurélio Dias da Silva e Ricardo de Marchi. São Paulo: Círculo do Livro e Editora Best Seller, 1997. 181 p.

As relações entre saú de e qualidade de vida constituem o pilar conceitual para a análise, o diagnóstico e mudanças dos hábitos, estilo de vida e visão de bem-estar no ambiente de trabalho. Os autores tratam de aspectos ligados a esses temas estimando os custos, informando sobre a implantação de programas e detal hando os fatores de risco, como o tabagismo e a vida sedentária. É uma obra médica com visão competente sobre a administração desses fatores nas empresas.

MUDANÇA SEM CATÁSTROFE OU CATÁSTROFE SEM MUDANÇAS: liderando pessoas para o processo de mudança. Héctor Rafael Lisondo. São Paulo: Casa do Psicólogo/ Uninove, 2004. 284 p.

A obra trata das transformações dos modelos organizacionais, no âmbito da empresa e do indivíduo. São apresentadas questões sobre as emoções, a satisfação, a saturação e a frustração. Discutese a atitude do "aprender a pensar e a mudar", fortal ecendo a compreensão sobre questões de liderança em ambientes de conflito e mudanças. O livro contribui efetivamente para uma nova forma de entender e administrar o comportamento das pessoas nas organizações contemporâneas.

NOTA DA REDAÇÃ 0: Os leitores são convidados a visitar a seção "Indicações de Pesquisa" da RAE-eletrônica (www.rae.com.br/eletronica) e conhecer os sites sugeridos pela autora. 